\title{
Regeneration of thyroid follicles from primordial cells in a murine thyroidectomized model
}

\author{
Junguee Lee', Shinae Yi², Joon Young Chang², Yea Eun Kang ${ }^{2}$, Hyun Jung Kim³ ${ }^{3}$ Ki Cheol Park ${ }^{3}$, Keum-Jin Yang ${ }^{3}$, \\ Hae Joung Sul ${ }^{1}$, Jong Ok Kim ${ }^{1}$, Hyon-Seung $\mathrm{Yi}^{2}$, Xuguang Zhu ${ }^{4}$, Sheue-yann Cheng ${ }^{4}$ and Minho Shong ${ }^{2}$
}

The functional unit of the thyroid gland, the thyroid follicle, dynamically responds to various stimuli to maintain thyroid hormone homeostasis. However, thyroid follicles in the adult human thyroid gland have a very limited regenerative capacity following partial resection of the thyroid gland. To gain insight into follicle regeneration in the adult thyroid gland, we observed the regeneration processes of murine thyroid follicles after partial resection of the lower third of the thyroid gland in 10-week-old male C57BL/6 mice. Based on sequential observation of the partially resected thyroid lobe, we found primitive follicles forming in the area corresponding to the central zone of the intact lateral thyroid lobe. The primitive thyroid follicles were multiciliated and had coarsely vacuolated cytoplasm and large vesicular nuclei. Consistently, these primitive follicular cells did not express the differentiation markers paired box gene-8 and thyroid transcription factor-1 (clone SPT24), but were positive for forkhead box protein A2 and leucine-rich repeat-containing G-protein-coupled receptor 4/GPR48. Follicles newly generated from the primitive follicles had clear or vacuolar cytoplasm with dense, darkly stained nuclei. At day 21 after partial thyroidectomy, the tall cuboidal follicular epithelial cells had clear or vacuolar cytoplasm, and the intraluminal colloid displayed pale staining. Smaller activated follicles were found in the central zone of the lateral lobe, whereas larger mature follicles were located in the peripheral zone. Based on these observations, we propose that the follicle regeneration process in the partially resected adult murine thyroid gland associated with the appearance of primitive follicular cells may be a platform for the budding of differentiated follicles in mice.

Laboratory Investigation (2017) 97, 478-489; doi:10.1038/labinvest.2016.158; published online 23 January 2017

The thyroid gland maintains systemic metabolic homeostasis through the production of thyroid hormones in follicular epithelial cells, which adapt to various physiologic and pathologic stimuli. Growth of the adult thyroid gland characterized by hyperplasia and hypertrophy of thyroid follicular epithelial cells is a chronic adaptive process to cope with the demand for thyroid hormones. However, regeneration of thyroid follicles following removal of part of the adult thyroid gland is minimal or insufficient to recover endocrine function. To investigate the regeneration processes, several studies observed the regeneration of thyroid follicles using mice that had undergone partial resection of the thyroid gland. ${ }^{1-3}$ Based on these observations, two models of thyroid regeneration have been proposed. One model proposes that immature endoderm lineage-committed progenitor cells, which are reprogrammed from mature cells, are the major contributor to follicle regeneration. ${ }^{4}$ Regeneration involving reprogramming and dedifferentiation of cells has been demonstrated in the lens and retina, ${ }^{5}$ skeletal muscle, ${ }^{6}$ adipose tissue, ${ }^{7}$ and renal tubules. ${ }^{8}$ Toda et al ${ }^{9}$ demonstrated new follicle formation from pre-existing follicles in threedimensional collagen gel cultures of thyroid tissue fragments. They observed three types of pre-existing follicle-derived folliculogenesis, namely, solid nest, budding, and lumendividing. This type of folliculogenesis has been observed in the early stage of embryonic thyroid morphogenesis ${ }^{10}$ and in the generation of new follicles in nodular goiter and hyperplastic Graves' disease. ${ }^{9,11,12}$ These observations suggest

${ }^{1}$ Department of Pathology, Daejeon St Mary's Hospital, College of Medicine, The Catholic University of Korea, Daejeon, Republic of Korea; ${ }^{2}$ Research Center for Endocrine and Metabolic Diseases, Division of Endocrinology, Department of Internal Medicine, Chungnam National University School of Medicine, Daejeon, Republic of Korea;

${ }^{3}$ Clinical Research Institute, Daejeon St Mary's Hospital, College of Medicine, The Catholic University of Korea, Daejeon, Republic of Korea and ${ }^{4}$ Gene Regulation Section, Laboratory of Molecular Biology, National Cancer Institut, NIH, Bethesda, MD, USA

Correspondence: Dr M Shong, MD, PhD, Research Center for Endocrine and Metabolic Diseases, Division of Endocrinology, Department of Internal Medicine, Chungnam National University School of Medicine, 266 Munhwa-ro, Jung-gu, Daejeon 35015, Republic of Korea.

E-mail: minhos@cnu.ac.kr

Received 5 December 2016; accepted 14 December 2016 
that pre-existing follicle-derived folliculogenesis is a plausible model of thyroid regeneration; however, it has not been demonstrated in an in vivo model of thyroid resection.

a

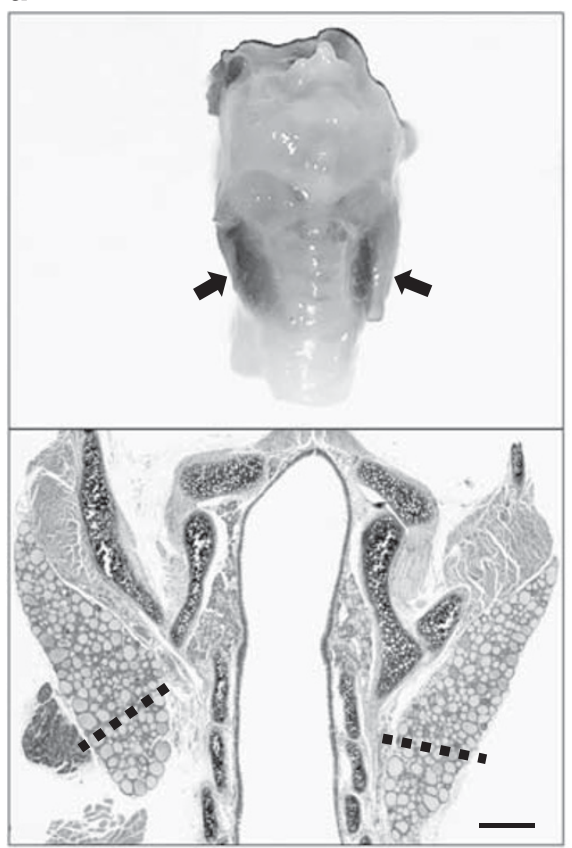

b

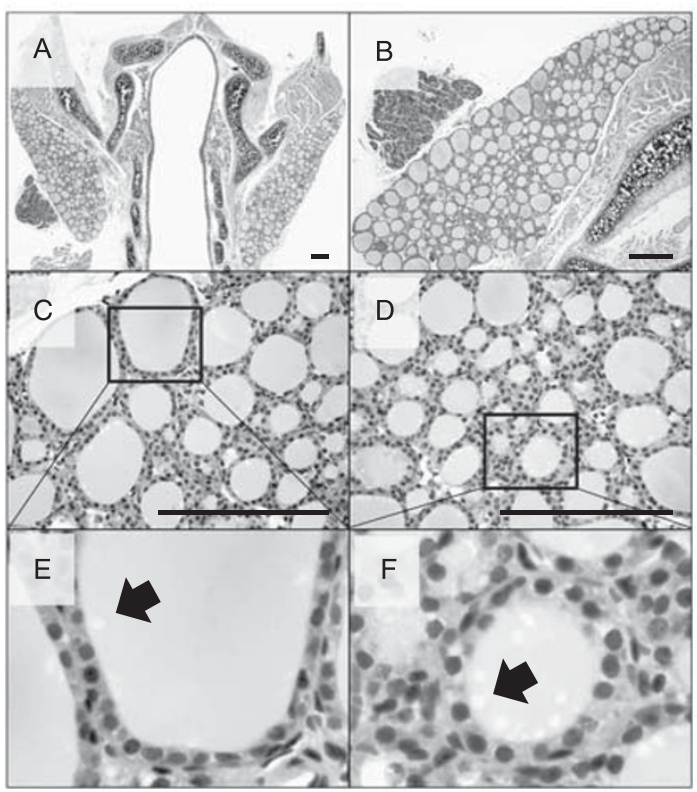

The other model proposes that activated adult-resident stem/progenitor cells participate in thyroid regeneration. ${ }^{13}$ Several studies provide clear evidence that the adult thyroid

c

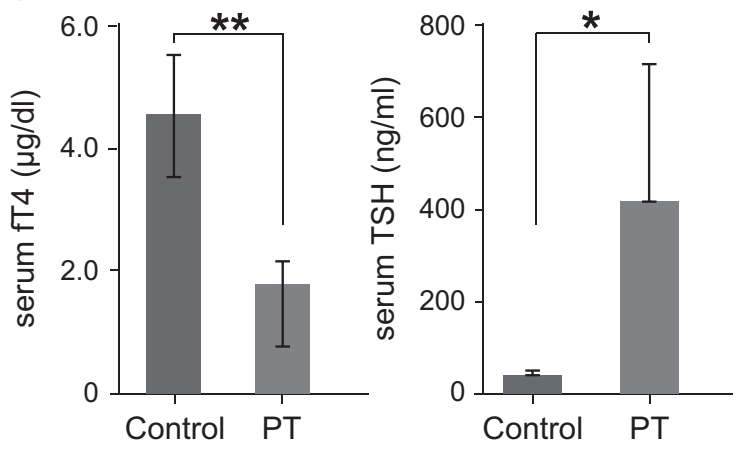

d

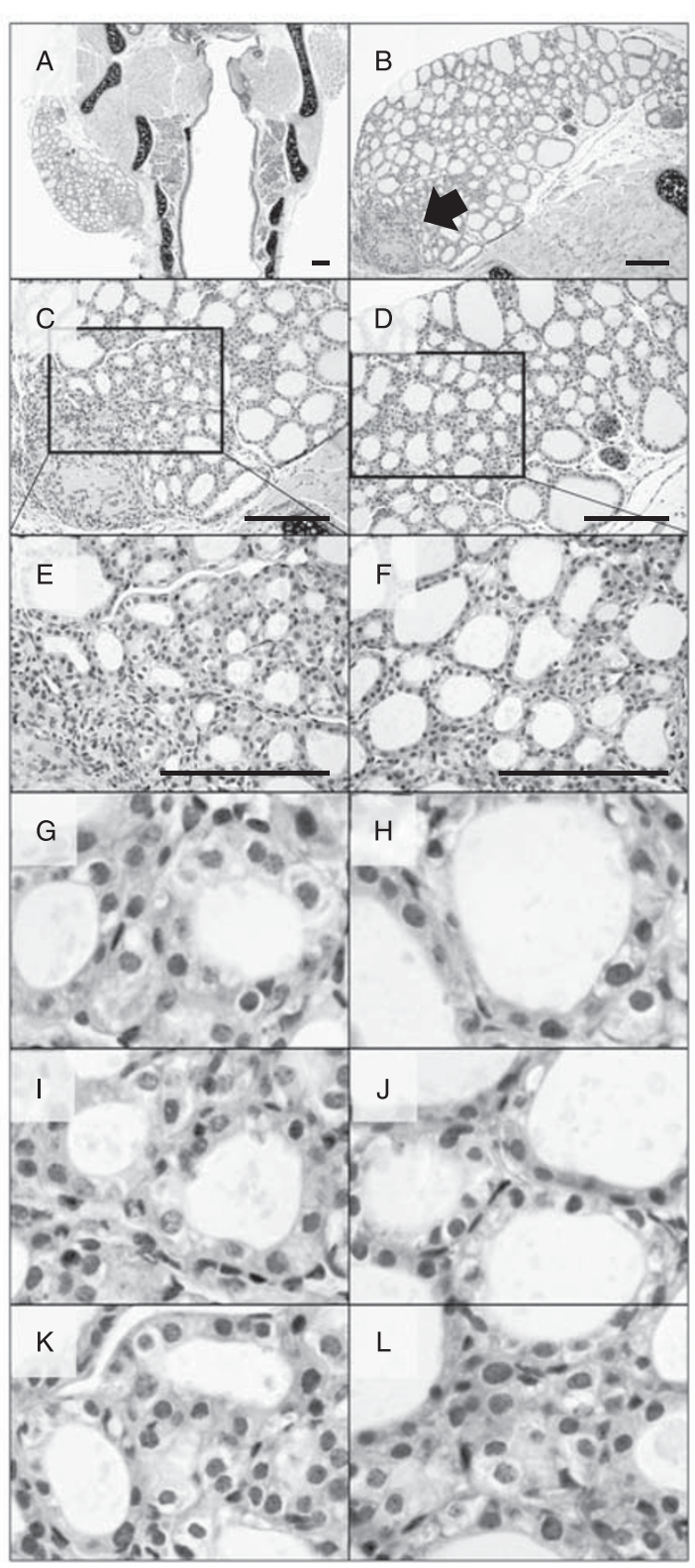

Figure 1 For caption see page 480. 
gland does indeed contain stem/progenitor cells, although the origin of these cells has not been determined. Side-population cells in the mouse thyroid gland highly express stem cell marker genes and exhibit stem/progenitor cell-like characteristics. ${ }^{14}$ When thyrospheres generated by culturing fresh surgically derived human thyroid specimens are seeded into collagen gels in differentiation medium, follicle-like structures form. ${ }^{15}$ The initial thyroid precursor, thyroid primordium, fuses with the ultimobranchial body (UBB) around E14.5 of mouse gestation. Thyroid transcription factor-1 (TTF-1, also called Nkx2.1) is one of the transcription factors that are critical for regulating the expression of genes involved in thyroid organogenesis. ${ }^{16}$ TTF-1 is expressed in the thyroid primordium and the UBB. ${ }^{17}$ Forkhead box protein A2 (FOXA2) is required for proper development of endodermal-derived organs such as the liver, pancreas, lung, and thyroid gland, and is thus considered to be a master regulator of early endoderm formation and endoderm lineage establishment. ${ }^{18}$ FOXA2 is an embryonic marker of the pharyngeal endoderm, lateral thyroid anlagen (UBB), and C cells. However, FOXA2 is specifically excluded from follicular progenitors in the median thyroid bud and is not expressed in thyroid follicles. ${ }^{19}$ Paired box gene-8 (PAX8) regulates maintenance of the phenotype of differentiated thyroid follicular cells, in which it controls and activates transcription of the main proteins responsible for follicular cell function, including thyroglobulin (Tg), thyroperoxidase, and sodium/ iodide symporter. ${ }^{20} \mathrm{PAX} 8$, like TTF-1, is first expressed in the median thyroid primordium. PAX8 is also expressed in the thyroglossal duct and the UBB. ${ }^{21}$ Although the thyroidspecific transcription factors TTF-1 and PAX8 are essential for development of the thyroid gland in both mice and humans, the role of these factors in regeneration remains to be determined. Furthermore, to determine the role of resident stem/progenitor cells, specific markers are required to define the pool of potential cells that exhibit stemness in the thyroid gland. Leucine-rich repeat-containing G-protein-coupled receptor 4 (LGR4)/GPR48 regulates embryonic growth ${ }^{22}$ and is required for stem cell maintenance in multiple organs, including the gallbladder, ${ }^{23}$ male reproductive tract, ${ }^{24,25}$ and hair follicles. ${ }^{26}$ mRNA expression of LGR4/GPR48 has been demonstrated in the thyroid gland, but the expression and role of LGR4/GPR48 in thyroid gland regeneration need to be determined.

In this study, we observed primitive follicles containing LGR4/GPR48-positive cells with coarsely vacuolated cytoplasm and large vesicular nuclei in the partially resected adult murine thyroid gland. Consistently, the primitive follicular cells did not express the differentiation markers PAX8 and TTF-1 (clone SPT24), but were positive for FOXA2 and LGR4/GPR48. We propose that the follicle regeneration process in the partially resected adult murine thyroid gland associated with the appearance of primitive follicular cells may be a platform for the budding of differentiated follicles in mice.

\section{MATERIALS AND METHODS \\ Animals}

Twenty-five, 10-week-old male C57BL/6J mice were anesthetized with ketamine and subjected to partial thyroidectomy to remove the lower third of the right and left lobes (Figure 1a). Mice were stabilized in a warm setting for $24 \mathrm{~h}$ to prevent death from hypothyroidism shock or bleeding. At postoperative days $7,10,21$, and 28 , the thyroid glands were dissected en bloc with the trachea and surrounding tissue for histological assessment. This study was approved by the Institutional Animal Care and Use Committee of the Clinical Research Institute, Daejeon St Mary's Hospital, The Catholic University of Korea. Animals were housed under pathogenfree conditions and received humane care in accordance with the criteria outlined in the Guide for the Care and Use of Laboratory Animals prepared by the Institute for Laboratory Animal Research, National Academy of Sciences.

\section{Histological Analysis}

Dissected tissues were fixed individually with $10 \%$ neutralbuffered formalin for $24 \mathrm{~h}$ at room temperature. After fixation, tissue blocks were embedded in paraffin. Paraffin blocks were trimmed to an optimal cutting surface including the thyroid gland. Paraffin-embedded whole thyroid glandcontaining blocks were cut into slices of $4 \mu \mathrm{m}$ in thickness at intervals of $50 \mu \mathrm{m}$. Tissue slices were routinely deparaffinized and then used for hematoxylin and eosin $(\mathrm{H} \& \mathrm{E})$ staining.

\section{Measurements of Thyroid Hormones in Serum and Thyroid Gland Activation Analysis}

Retro-orbitally collected, clotted mouse blood was centrifuged at $3000 \mathrm{~g}$ for $10 \mathrm{~min}$. Sera were separated and stored at $-20^{\circ} \mathrm{C}$ before the hormonal assays. Serum-free T4 (fT4) levels were measured using an Enzyme-Linked Immunosorbent Assay Kit (Merck Millipore) according to the manufacturer's instructions. The serum level of thyroid-stimulating hormone (TSH)

Figure 1 (a) The lower third of the right and left lobes of the mouse thyroid was removed. Bilateral en bloc resection (upper panel) and an hematoxylin and eosin (H\&E)-stained section (lower panel) of the thyroid gland. Scale bar, $60 \mu \mathrm{m}$. (b) A normal thyroid gland from a 12-week-old control mouse is shown. Arrow, endocytic vacuoles in intraluminal colloid. H\&E staining. Scale bar, $30 \mu \mathrm{m}$. (c) The mean serum level of serum-free T4 (fT4) in partially thyroidectomized (PT) mice was decreased to $1.76 \pm 0.37 \mu \mathrm{g} / \mathrm{dl}$ at postoperative day 7 compared with that in the sham operation group $(P=0.004)$. ${ }^{* *} P<0.01$. The mean serum thyroid-stimulating hormone (TSH) level in PT mice was increased to $414.49 \pm 294.89 \mathrm{ng} / \mathrm{ml}$ at postoperative day 7 compared with that in the sham operation group $(P=0.040)$. ${ }^{*} P<0.05$. (d) Representative images show thyroid follicles at 7 days after PT. H\&E staining. Scale bar, $30 \mu \mathrm{m}$. 
a
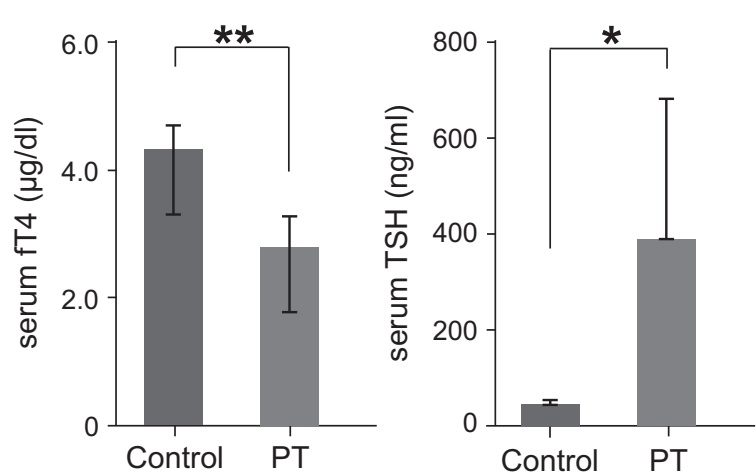

C

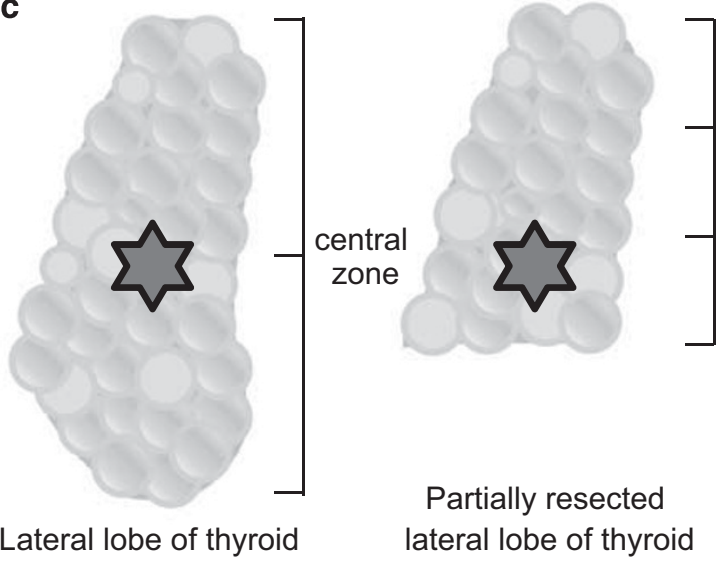

b

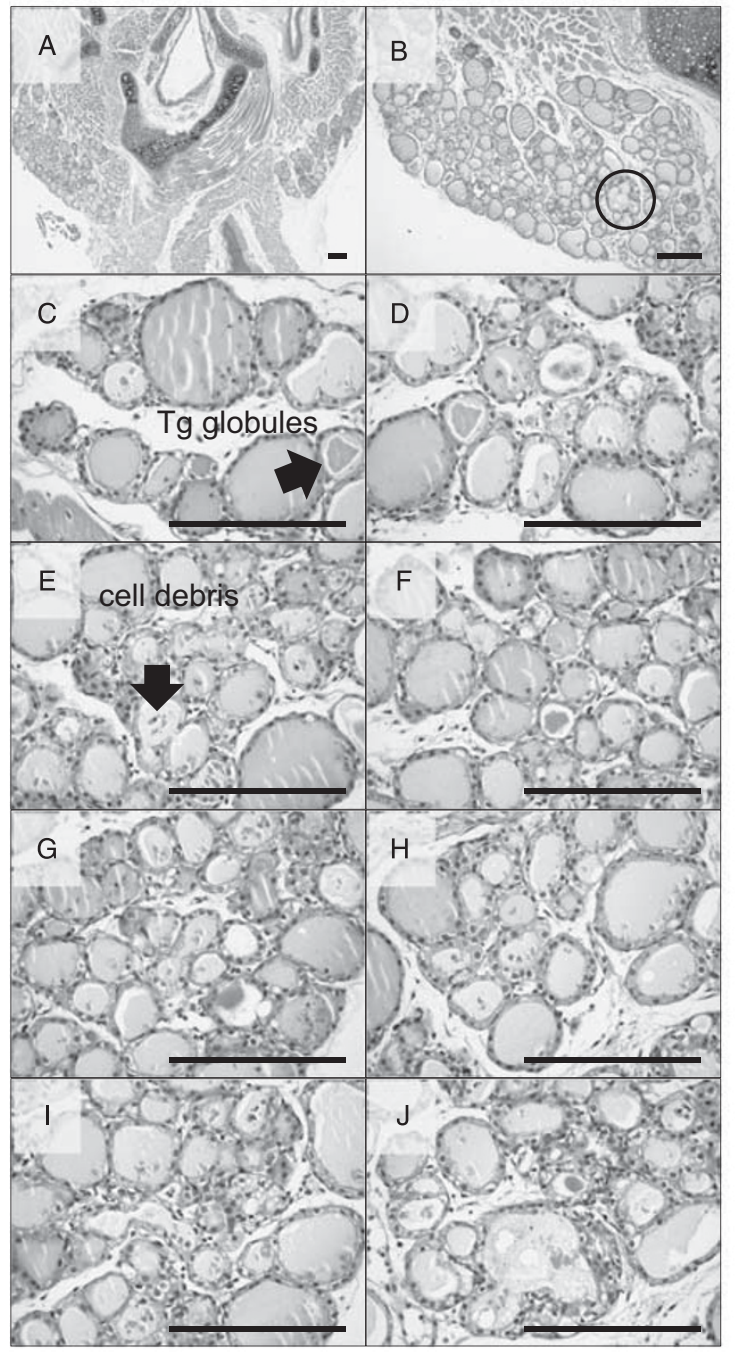

d

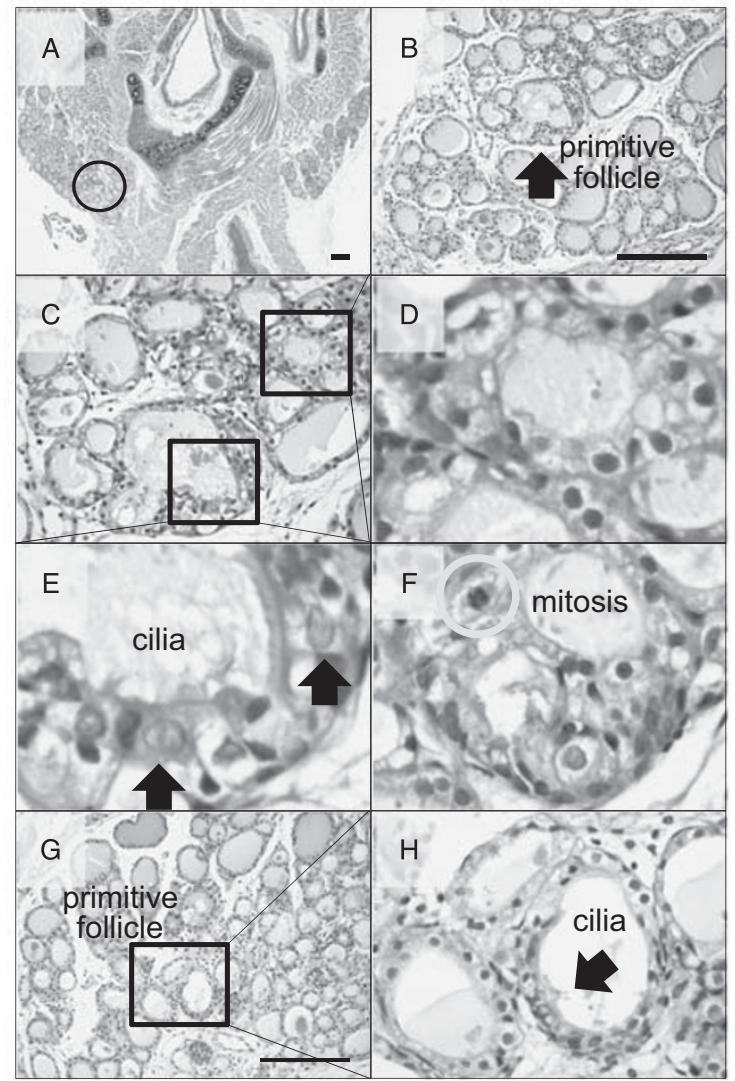

e

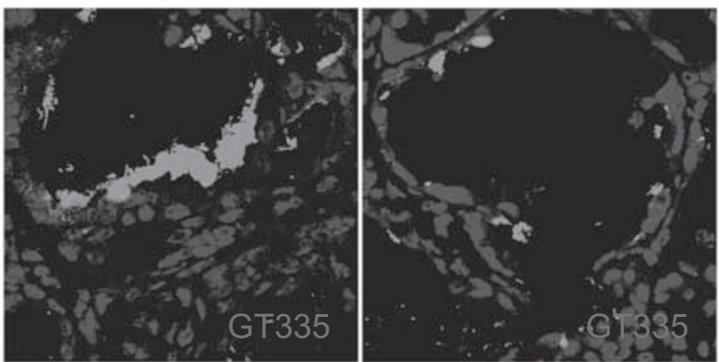

Figure 2 For caption see page 482. 
was measured using a specific mouse TSH radioimmunoassay provided by Dr Cheng (Center for Cancer Research, National Cancer Institute, Bethesda, MD, USA).

Thyroid gland activity was estimated indirectly using the thyroid activation index, which is correlated with the serum level of $\mathrm{TSH}^{27}$ The thyroid activation index was expressed as the epithelial-to-colloid volume density ratio. ${ }^{27}$

\section{Immunohistochemical Analysis}

Paraffin-embedded tissue sections ( $4 \mu \mathrm{m}$ thick) were placed in an oven and incubated at $56^{\circ} \mathrm{C}$ for $3 \mathrm{~h}$ before immunohistochemistry. Specimens were stained using an automatic Ventana HX BenchMark system (Ventana Medical Systems, SA, Illkirch Cedex, France) with an anti-TTF-1 (clone SPT24; Novocastra/Leica, Newcastle upon Tyne, England), antiFOXA2 (Seven Hills Bioreagents, Cincinnati, OH, USA), monoclonal anti-PAX8 (Abcam, Cambridge, UK), or polyclonal anti-LGR4/GPR48 (Bioss, Woburn, MA, USA) antibody. All procedures, including antigen retrieval and blocking of endogenous peroxidase activity, were performed automatically. Tissue sections were incubated with primary antibodies for $32 \mathrm{~min}$ at $42^{\circ} \mathrm{C}$. Immunoperoxidase staining was performed using the LSAB NeuVision system, according to the manufacturer's instructions (Ventana), and sections were counterstained with hematoxylin. Tissue slides were analyzed using an OLYMPUS BX51 microscope (Olympus).

TTF-1 is expressed in the nuclei of most follicular epithelial cells. TTF-1 expression in primitive follicles was examined based on sequential observation of the partially resected thyroid lobe. When the follicular cells of these primitive follicles were completely negative for TTF-1, the follicles were considered to be TTF-1-negative. FOXA2 is expressed in the nuclei of the endoderm-derived primitive thyroid gland. Expression of PAX8 is distinct in follicular epithelial cells and is dispersed throughout the thyroid gland in adult mice. Expression of FOXA2 and PAX8 was analyzed in primitive follicles with a basal/stem cell appearance or multiciliated follicles. LGR4/GPR48 predominantly localizes to the plasma membrane; therefore, cells with membranous expression of LGR4/GPR48 were judged to be positive for this marker.

\section{RESULTS}

\section{Establishment of a Mouse Model with Bilateral Resection} of the Thyroid Lobes

To observe the regeneration of thyroid follicles in vivo, we used a mouse (C57BL/6J) model with bilateral partial resection of the thyroid lobes (Figure 1b). Control male mice aged 12 weeks showed homogeneously round and variably sized follicles surrounded by cuboidal follicular epithelial cells (Figure 1b). Larger follicles were mostly located in the subcapsular peripheral region of the thyroid gland, whereas smaller follicles tended to be observed in the central region of the lateral thyroid lobes. This zonal distribution of larger and smaller follicles might be attributed to the finding that newly formed follicles are generated in the center of the thyroid gland and are pushed to the peripheral zone during maturation. ${ }^{28,29}$ All thyroid follicles in control mice were homogeneously filled with colloid stained with eosin. Colloid in follicles located in the peripheral zone was stained darker than that in follicles located in the central zone. It has been suggested that intraluminal colloid density correlates with follicular activity, which is linked with thyroid hormone formation. ${ }^{30}$ More darkly stained colloid and Tg globules might be more frequent in hypofunctioning follicles than in active follicles. In the control group, many endocytic vacuoles were seen near to the margin of the colloid-filled lumen (Figure 1b). The number of endocytic vacuoles in intraluminal colloid was higher in the central zone of the lateral lobe than in the peripheral zone (Figure $1 \mathrm{bE}$ and F, arrow). Colloid endocytosis also correlates with follicular cell activity. ${ }^{31}$

\section{Early Thyroid Hormone Changes in Mice that have Undergone Thyroid Lobectomy}

The mean serum level of fT4 was $1.76 \pm 0.37 \mu \mathrm{g} / \mathrm{dl}$, for a TSH of $414.49 \pm 294.89 \mathrm{ng} / \mathrm{ml}$ in partially thyroidectomized mice at postoperative day 7. Control mice had a mean serum fT4 level of $4.48 \pm 0.96 \mu \mathrm{g} / \mathrm{dl}$ and TSH level of $40.49 \pm 9.21 \mathrm{ng} / \mathrm{ml}$ after the sham operation (Figure 1c). In partially thyroidectomized mice at postoperative day 10 , the mean serum $\mathrm{fT} 4$ level was still reduced $(2.74 \pm 0.48 \mu \mathrm{g} / \mathrm{dl}, P=0.0002)$ with an elevation of serum TSH $(384.02 \pm 286.96 \mathrm{ng} / \mathrm{ml}, P=0.031)$ (Figure 2a). The reduced serum level of fT4 suggested that the remaining thyroid gland in the mouse model of partial thyroidectomy cannot produce a sufficient amount of T4.

\section{Early Morphological Changes in Follicles after Resection of the Thyroid Lobes}

We removed the thyroid glands in mice 7 days after partial thyroidectomy. The margin of resection in thyroid lobes was marked by granulation tissue (Figure $1 \mathrm{~dB}$, arrow). Follicles located in the margin of resection were irregularly shaped and

Figure 2 Thyroid hormone change and histological analysis of thyroid sections at 10 days after partial thyroidectomy (PT). (a) The mean serum level of serum-free T4 (fT4) in PT was decreased to $2.74 \pm 0.48 \mu \mathrm{g} / \mathrm{dl}$ at postoperative day 10 compared with $4.25 \pm 0.37 \mu \mathrm{g} / \mathrm{dl}$ in the sham operation group $(P=0.0002)$. ${ }^{* *} P<0.01$. The mean serum TSH level in PT was increased to $384.02 \pm 286.96 \mathrm{ng} / \mathrm{ml}$ at postoperative day 10 compared with $43.49 \pm 9.05 \mathrm{ng} / \mathrm{ml}$ in the sham operation group $(P=0.031)$. ${ }^{*} P<0.05$. (b) Representative sequential images of the thyroid gland from the upper pole to the cutting margin. Hematoxylin and eosin (H\&E) staining. Scale bar, $30 \mu \mathrm{m}$. (c) Schematic images show the central zone in the intact lateral lobe and the partially resected lateral lobe of the thyroid gland. (d) Representative images show regeneration centers of the thyroid gland. H\&E staining. Scale bar, $30 \mu \mathrm{m}$. (e) Cilia in primitive follicular cells are immunoreactive to GT335, a monoclonal antibody directed against polyglutamylated tubulins. 
a
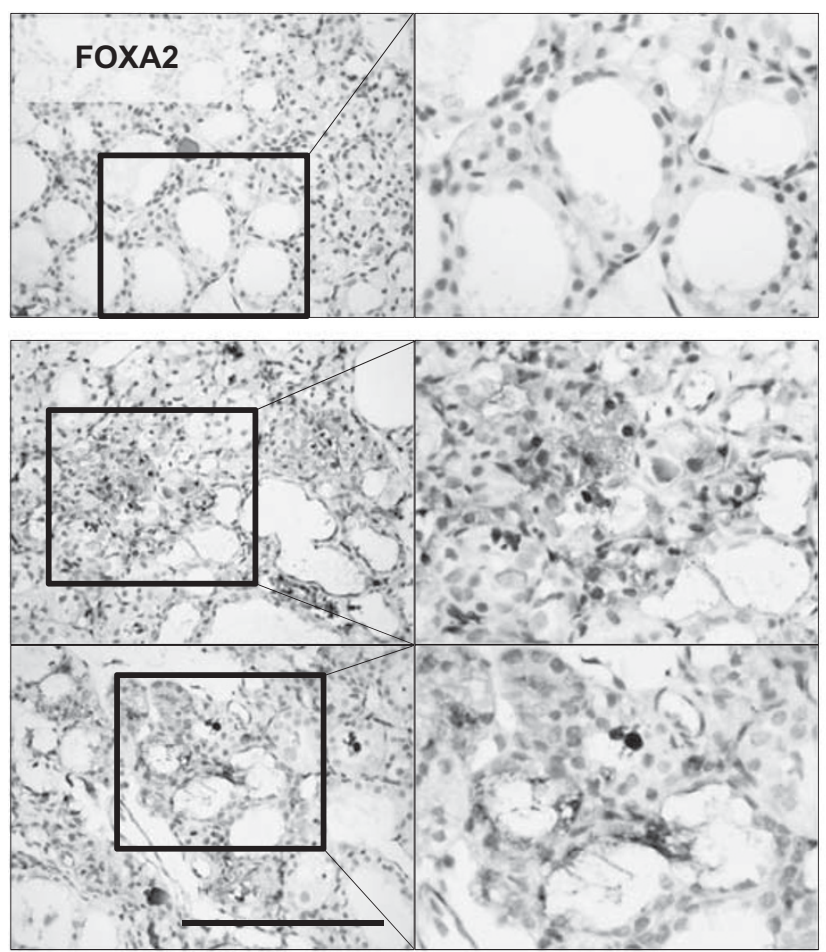

b

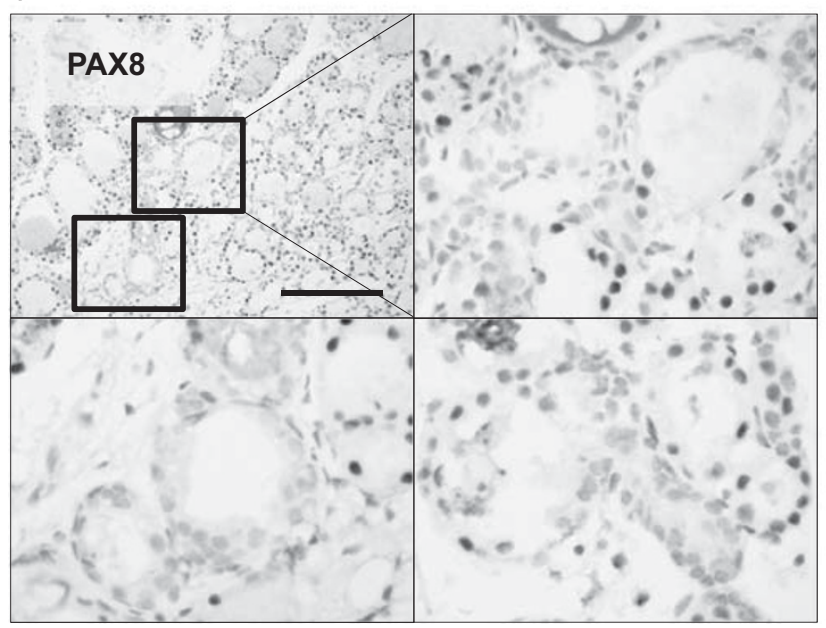

C

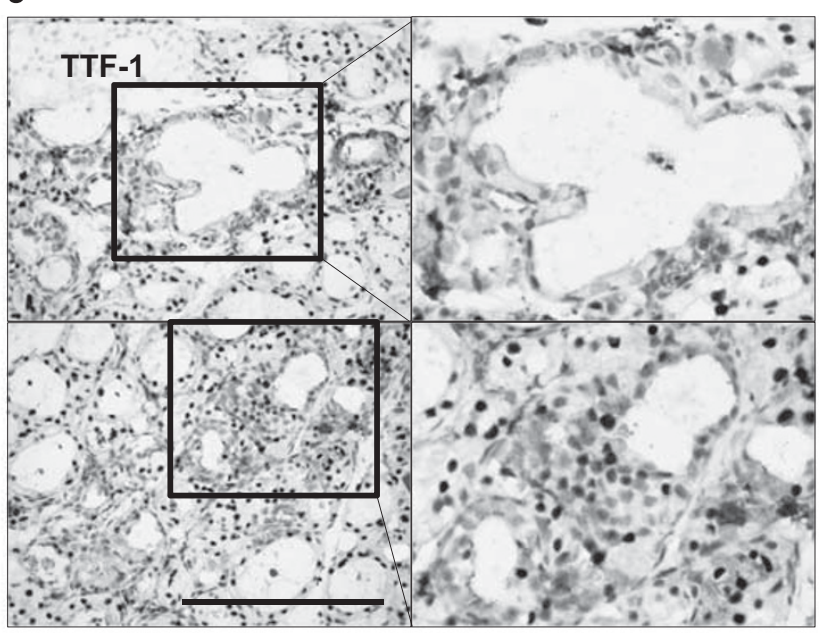

d

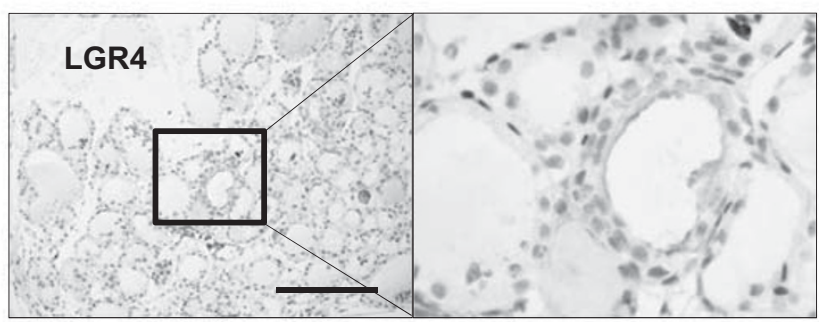

Figure 3 Immunohistochemical analysis of thyroid follicles at 10 days after partial thyroidectomy. (a) The primitive follicles exhibiting budding expressed Forkhead box protein A2FOXA2 in nuclei, although most follicular cells were negative for Forkhead box protein A2 (FOXA2). (b) The primitive follicles exhibiting budding were weakly positive or negative for paired box gene-8 (PAX8). (c) The primitive follicles exhibiting budding were negative for thyroid transcription factor-1 (TTF-1). (d) The primitive follicles exhibiting budding demonstrated apical membrane leucine-rich repeat-containing G-protein-coupled receptor 4 (LGR4)/GPR48 expression. Scale bar, $30 \mu \mathrm{m}$.

smaller than those in the other region of the thyroid lobes (Figure 1dE). The height of most follicular cells was increased, and intraluminal colloid appeared pale pink. Follicular cells with dense, darkly stained or vesicular nuclei and clear, pale eosinophilic or vacuolar cytoplasm were dispersed throughout the entire thyroid gland (Figure 1d). We considered these histological changes in follicles to represent activation of follicular cells that arose after partial thyroidectomy. There were more mitotic cells in thyroidectomized mice than in control mice. In the central zone of the lateral lobe, thyroid follicles did not show any marked changes (Figures $1 \mathrm{dD}$ and $\mathrm{F}$ ).

At day 10 after partial thyroidectomy, follicles in the upper pole had densely stained colloid and contained Tg globules or cell debris (Figure $2 \mathrm{bC}$ and $\mathrm{D}$ ). ${ }^{32}$ In the area corresponding to the center of the intact lateral lobe of the thyroid gland (lower 
one-third of the remaining lateral lobe in the partially resected thyroid gland; Figure 2c), a few follicles had a primitive morphology and consisted of multiciliated follicular cells with coarsely vacuolated cytoplasm and large vesicular nuclei (Figure 2dE, arrow). These follicles with a primitive morphology had protruding buds similar to feather primitive follicles and a small amount of or no luminal colloid. The follicles around primitive follicles had a clear or vacuolar cytoplasm with dense, darkly stained nuclei (Figure 2dD). The appearance of vesicular nuclei is an indication of heightened levels of hormonal and protein activity, which indicates that the cells were in an active and aggressive growth phase. ${ }^{33}$ Mitosis was observed in some instances (Figure 2dF, circle). These characteristic morphologies indicate that the follicles located around primitive follicles were newly regenerated. Follicle formation from primitive follicles was the budding type of mother follicle-derived folliculogenesis (Figures $2 \mathrm{bB}$ and c). ${ }^{9}$ We used the GT335 antibody to detect cilia (Figure 2e). GT335, a monoclonal antibody directed against polyglutamylated tubulins, stained the centriole/basal body and the axoneme of ciliated cells, and the centriole of nonciliated cells. ${ }^{34}$

These primitive follicles exhibiting budding expressed FOXA2 in nuclei, although most follicular cells were negative for FOXA2 (Figure 3a). PAX8 is a transcription factor crucial for organogenesis and development of the thyroid gland. Strong PAX8 positivity was observed in all nuclei of follicular cells in the control group. Although most follicular cells showed strong PAX8 positivity, those of follicles exhibiting budding were weakly positive or negative for PAX8 (Figure $3 \mathrm{~b}$ ). The follicles exhibiting budding were negative for TTF-1, although most follicular cells showed TTF-1 positivity (Figure 3c). These follicular cells exhibited apical membrane LGR4/GPR48 expression (Figure 3d). LGR4/ GPR48 has an important role in cell proliferation, differentiation, and adult stem cell homeostasis. ${ }^{35}$ These results suggest that follicles exhibiting budding are primitive thyroid follicles (the so-called mother follicles).

\section{Late Thyroid Hormone Changes in Mice that have Undergone Thyroid Lobectomy}

In partially thyroidectomized mice at postoperative day 28 , the mean serum level of fT4 returned to normal values $(4.03 \pm 0.41 \mu \mathrm{g} / \mathrm{dl}, P=0.47)$ and the mean serum TSH level was elevated $(58.64 \pm 15.69 \mathrm{ng} / \mathrm{ml}, P=0.02)$. Control mice had a mean serum fT4 level of $4.13 \pm 1.39 \mu \mathrm{g} / \mathrm{dl}$ and TSH level of $38.07 \pm 7.23 \mathrm{ng} / \mathrm{ml}$ after the sham operation (Figure $5 \mathrm{a}$ ).

\section{Late Morphological Changes in Mice that have Undergone Thyroid Lobectomy}

At day 21 after partial thyroidectomy, we analyzed H\&Estained slides from serial sections at $50 \mu \mathrm{m}$ intervals (Figure 4a). In the first section, there was a relatively homogeneous population of small- to medium-sized round follicles lined with short cuboidal follicular cells (Figure 4aA). In the second, third, fourth, and fifth sections, tall cuboidal follicular epithelial cells were observed with a clear or vacuolar cytoplasm and pale intraluminal colloid (Figure $4 \mathrm{aB}$ ). These morphological changes were associated with functional activation of thyroid follicles. Smaller follicles with an activated morphology were found in the central zone of the lateral lobe, whereas larger follicles were located in the peripheral zone (Figures $4 \mathrm{~b}-\mathrm{e}$ ). In the third, fourth, and fifth sections, we found multiciliated follicular cells, which are considered to be primitive follicles (Figure 4a, circle). Figure $4 \mathrm{f}$ shows reconstruction of these follicles from serial sections. There were primitive follicles in the central zone of the lateral thyroid lobe. The budding type of folliculogenesis occurred in primitive follicles. Smaller follicles with an activated morphology were located around primitive ciliated follicles, and larger matured follicles were located in the peripheral zone of the thyroid gland. Further examination of the area revealed that the space between previously formed follicles was filled with newly regenerated follicles (Figure 4f). The presence of irregularly dilated and empty follicles lined with flattened epithelium was occasionally noted at the periphery of the cutting margin. These follicles might be nonfunctional and atrophic (Figures $4 \mathrm{cC}$ and $\mathrm{dC}$ ). Collectively, these results suggest that after partial thyroidectomy, primitive thyroid follicles in the center of the lateral thyroid lobe underwent a regeneration process, the budding type of folliculogenesis, to produce new follicles.

Interestingly, we observed primitive thyroid follicles exhibiting the lumen-dividing type of folliculogenesis in the intramuscular spaces of the sternothyroid muscle (Figure 4G). Three $\mathrm{H} \& \mathrm{E}$-stained images from serial sections at $50 \mu \mathrm{m}$ intervals are shown in Figure 4gB. Epithelial cells of thyroid follicles grew papillary projections into the follicle lumen. Their progressive extensions divided the follicle lumen into several smaller lumens, giving rise to multiluminal follicles. These follicles were considered to be ectopic foci of newly regenerated follicles.

At day 28 after partial thyroidectomy, primitive thyroid follicles were detected not only in the central zone of the lateral lobe in the intact thyroid gland (Figure $5 \mathrm{c}$ ) but also at the cutting margin of the partial thyroidectomy site (Figure $5 \mathrm{~b}$ ). The budding type of folliculogenesis was noted

Figure 4 Histological analysis of thyroid sections at 3 weeks after partial thyroidectomy. (a) Six representative serial sections are shown. The circle indicates the budding type of mother follicle-derived folliculogenesis. Boxed and circled regions are magnified in (b-e). (f) Reconstruction of follicles from serial sections is shown. (g) Lumen-dividing type of folliculogenesis is observed in the intramuscular spaces of the sternothyroid muscle. Arrow, ciliated primitive thyroid follicular epithelial cells; arrow head, papillary projections of a thyroid follicular epithelial cell. $\mathrm{m}$, skeletal muscle. Hematoxylin and eosin (H\&E) staining. Scale bar, $30 \mu \mathrm{m}$. 
a
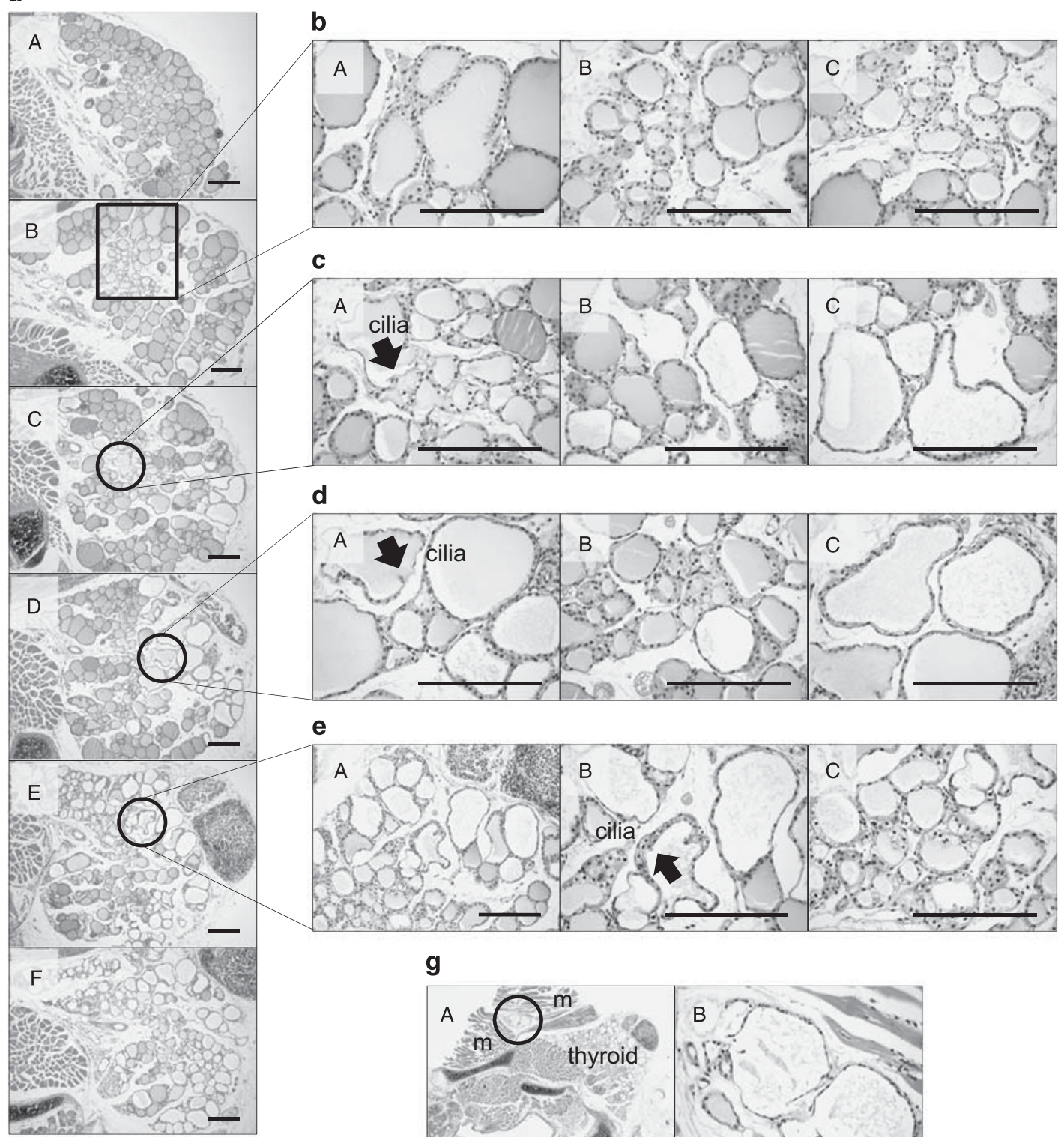

g
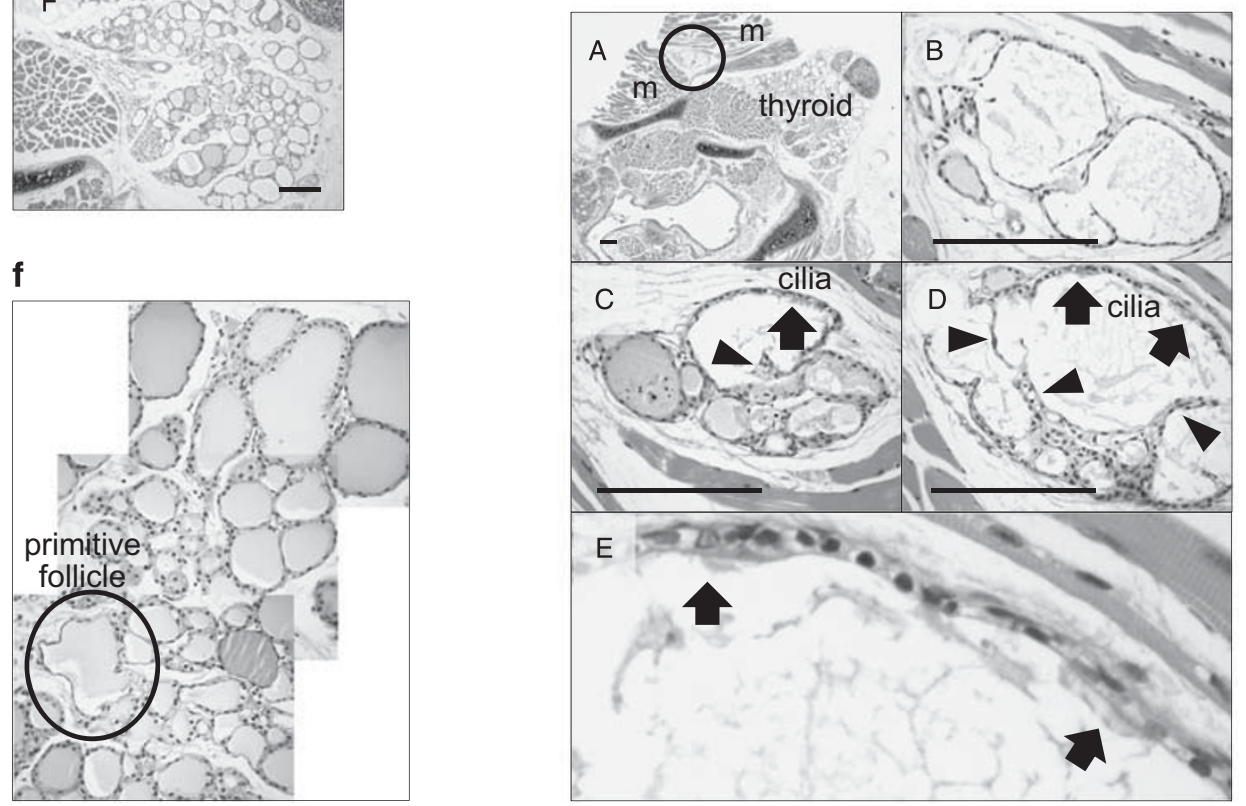

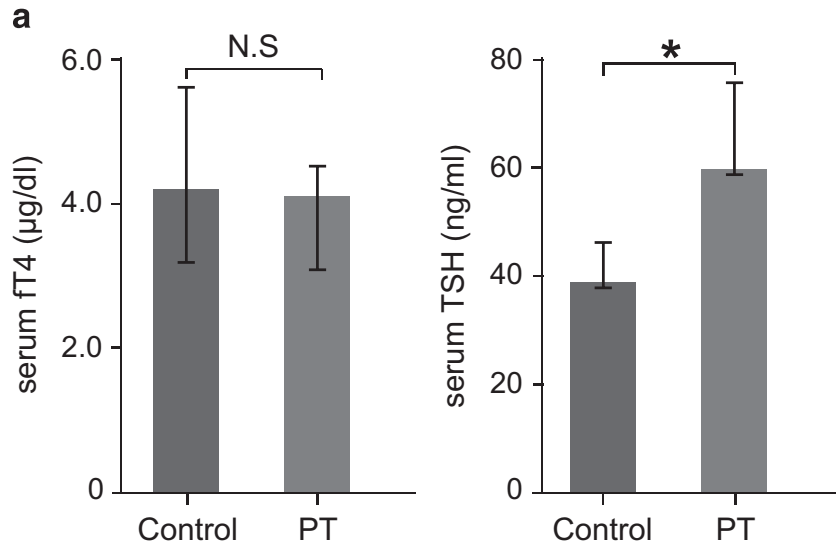

b

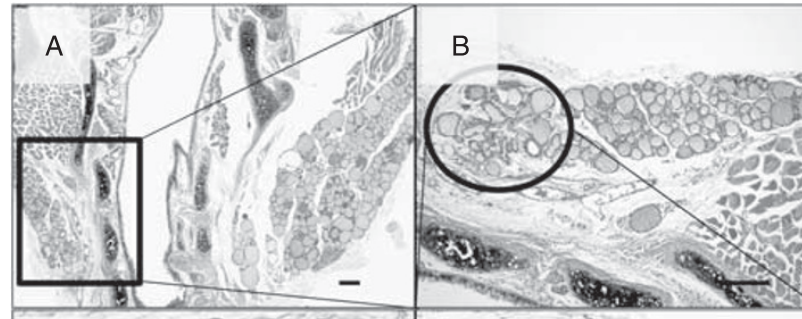

c
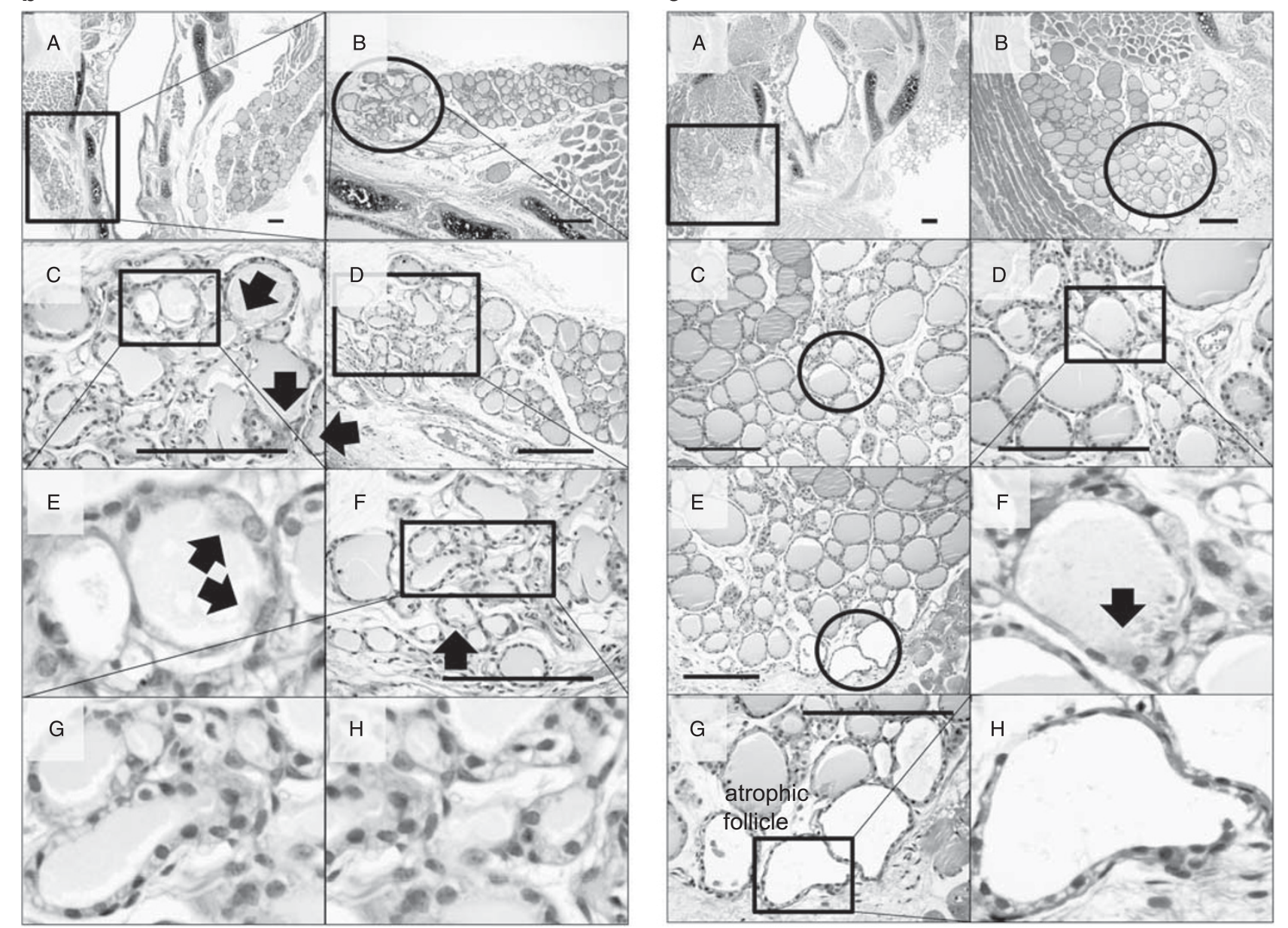

Figure 5 Thyroid hormone change and histological analysis of thyroid sections at 4 weeks after partial thyroidectomy. (a) The mean serum level of serum-free T4 (fT4) in partially thyroidectomized (PT) returned to normal values, $4.03 \pm 0.41 \mu \mathrm{g} / \mathrm{dl}$ compared with $4.13 \pm 1.39 \mu \mathrm{g} / \mathrm{dl}$ in the sham operation group $(P=0.47)$. NS, no statistical significance. The mean serum TSH level in PT was slightly elevated to $58.64 \pm 15.69 \mathrm{ng} / \mathrm{ml} \mathrm{compared} \mathrm{with}$ $38.07 \pm 7.23 \mathrm{ng} / \mathrm{ml}$ in the sham operation group $(P=0.02)$. ${ }^{*}>0.05$. (b and $\left.\mathbf{c}\right)$ Arrow, primitive ciliated thyroid follicular epithelial cells. Hematoxylin and eosin (H\&E) staining. Scale bar, $30 \mu \mathrm{m}$.

at the cutting margin (Figure 5bC). These follicles were irregularly shaped and contained pale pink colloid. There were multiciliated cells with large vesicular nuclei and coarsely vacuolated cytoplasm (Figure 5bF). The level of folliculogenesis in the central zone of the lateral thyroid lobe was lower than that at postoperative week 3 (Figure 5c). Atrophic follicles were also found at the periphery of the cutting margin (Figure 5cE).

Based on the finding that the follicle density increased in the remaining lobe of partially thyroidectomized mice after 
a

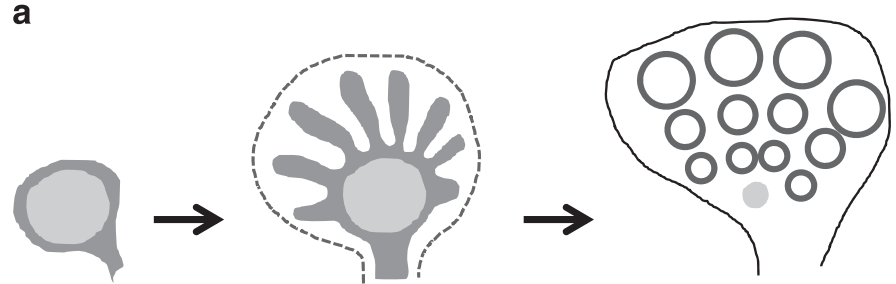

b

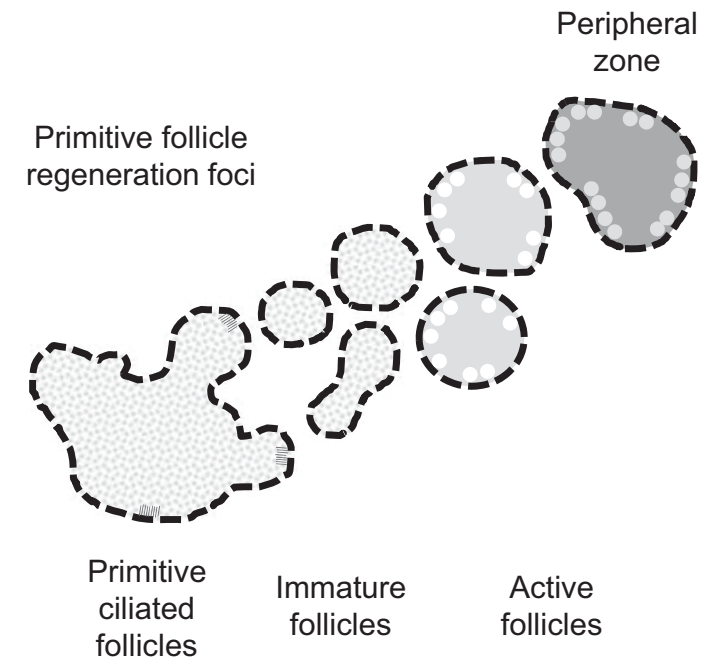

Figure 6 (a) Folliculogenesis based on a model of parenchymal growth from regeneration centers in mouse. The ultimobranchial body (UBB) remnants are indicated in orange (refer to Fagman et $a^{37}$ ). (b) Schematic model of the budding type of mother follicle-derived folliculogenesis in the adult thyroid gland.

4 weeks, new follicles could be generated throughout the remaining lobe following partial thyroidectomy. The cutting margin of the partial thyroidectomy site also contained newly generated follicles. However, the appearance of these follicles did not precede that in the other regions of the remaining lobe following partial thyroidectomy.

\section{DISCUSSION}

Recent studies demonstrated that adult stem/progenitor cells are responsible for the thyroid regeneration processes; ${ }^{13,14}$ however, little is known about the cellular and molecular processes of follicular cell regeneration in the adult thyroid gland. In this study, we demonstrated for the first time that the budding type of folliculogenesis occurs via primitive thyroid follicles in the partially resected thyroid gland of an adult rodent model. We called these foci the regeneration centers, which were located in the central zone of the lateral lobe. We found two types of characteristic follicular cells in the regeneration centers: multiciliated and immature follicular cells. The ciliated cells were characterized by large vesicular nuclei and coarsely vacuolated cytoplasm, and were located in primitive follicles. The immature follicular cells were characterized by dense, darkly stained nuclei and clear, pale eosinophilic or vacuolar cytoplasm, and were found in newly regenerated follicles derived from the primitive follicles. The primitive ciliated follicular cells did not express the differentiation markers PAX8 and TTF-1 (clone SPT24), but did express FOXA2 and LGR4/GPR48. An elevated circulating level of TSH promoted expression of the thyroid-specific transcription factors PAX8 and TTF-1 in matured thyroid follicular cells. The decreased immunoexpression of PAX8 and TTF-1 reduced the response to the elevated TSH level in multiciliated follicular cells. These findings suggest that the primitive multiciliated cells are primordial follicular cells that may not have undergone terminal differentiation. The primitive follicular cells with occasional cilia lying inside them are considered to be embryonic remnants of the thyroid primordium. ${ }^{17,36}$ The central zone of the lateral lobe where primitive follicles exist is a fusion point of the median thyroid primordium and the UBB during embryogenesis. In the presumptive lobes, parenchymal cells form columnar cords projecting from the center to the peripheral zone, septated by connective tissue containing microvascular networks. Subsequently, as the parenchymal cords continue to elongate by cell proliferation predominantly at the tips, they become gradually segmented and convert to diminutive follicles that become vascularized by capillaries (Figure 6a). ${ }^{37}$ The folliculogenesis process that occurred after partial thyroidectomy displayed similar characteristics.

At day 7 after partial thyroidectomy, large follicular cells with a clear, pale eosinophilic or vacuolar cytoplasm were dispersed throughout the entire thyroid gland. The clear or vacuolar cytoplasm is the result of uptake of $\mathrm{Tg}$ stored in intraluminal colloid. At postoperative week 3, follicular cells 
with a flat or short cuboidal morphology were found throughout the entire thyroid tissue, except the regeneration center. Toward the peripheral zone, immature follicles derived from the primitive thyroid follicles underwent a maturation process. Follicles in the peripheral zone had many endocytic vacuoles in the margin of the colloid-filled lumen and vesicular cytoplasm. A distinctive feature of follicular cells engaged in protein synthesis is the presence of several vesicles localized in the apical or subapical cytoplasm. ${ }^{38}$ These vesicles are exocytotic vesicles containing newly synthesized Tg. Thus, the follicles with endocytic vacuoles and vesicular cytoplasm at the peripheral zone were formed by newly regenerated follicles derived from primitive follicles at the central zone through the maturation process (Figures $4 \mathrm{f}$ and $6 \mathrm{~b}$ ). Ozaki et $a l^{2}$ reported that proliferation centers in the mouse thyroid gland are localized at the central zone of the lateral thyroid lobe. ${ }^{2}$ They showed that thyroid regeneration occurs after partial thyroidectomy with preservation of the central zone of the lateral lobe. However, if more than half of the thyroid gland is resected, regeneration does not occur. ${ }^{2}$ These results support the proposal that the aforementioned primitive follicles found in the central zone of the lateral lobe are responsible for adult thyroid regeneration.

The serum level of fT4 at postoperative day 7 was reduced by twofold compared with that in control mice. The serum TSH level was markedly increased at postoperative day 7 . Circulating concentrations of thyroid hormones are regulated by negative feedback loops within the hypothalamic-pituitarythyroid axis. ${ }^{39}$ Thus, the elevated serum TSH is due to compensatory increases in hypothyroidism. TSH is a main differentiating factor for thyroid follicular cells. ${ }^{40}$ Increased TSH levels are associated with increased thyroid cell proliferation and stimulation of $\mathrm{T} 3$ and $\mathrm{T} 4$ production. However, it has not been clearly determined whether thyroid folliculogenesis or regeneration is TSH-independent ${ }^{41,42}$ or TSH-dependent. ${ }^{43,44}$ Although our results demonstrate that thyroid folliculogenesis is partly TSH-dependent in adult rodents, other factors may also be involved in thyroid folliculogenesis.

The basic mechanisms of follicle regeneration are largely unclear. Currently, no markers are available to identify adult stem cells that can form thyroid follicular cells. We suggest that primitive ciliated cells with large vesicular nuclei and coarsely vacuolated cytoplasm are involved in folliculogenesis. Based on our observations, we propose that the follicle regeneration process in the partially resected adult murine thyroid gland associated with the appearance of primitive follicular cells may be a platform for the budding of differentiated follicles in mice. More studies are needed to confirm these results in other models.

\section{ACKNOWLEDGMENTS}

This work was supported by a grant from Daejeon St Mary's Hospital, The Catholic University of Korea (grant number: CMCDJ-A-2015-003) and by a grant from the Basic Science Research Program through the National
Research Foundation of Korea (NRF) funded by the Ministry of Science, ICT \& Future Planning (grant number: NRF-2015R1C1A1A02037434).

\section{DISCLOSURE/CONFLICT OF INTEREST}

The authors declare no conflict of interest.

1. Dumont JE, Lamy $\mathrm{F}$, Roger $\mathrm{P}$, et al. Physiological and pathological regulation of thyroid cell proliferation and differentiation by thyrotropin and other factors. Physiol Rev 1992;72:667-697.

2. Ozaki T, Matsubara $\mathrm{T}$, Seo $\mathrm{D}$, et al. Thyroid regeneration: characterization of clear cells after partial thyroidectomy. Endocrinology 2012;153:2514-2525.

3. Okamoto M, Hayase S, Miyakoshi M, et al. Stem cell antigen 1-positive mesenchymal cells are the origin of follicular cells during thyroid regeneration. PLoS One 2013;8:e80801.

4. Sugimoto K, Gordon SP, Meyerowitz EM. Regeneration in plants and animals: dedifferentiation, transdifferentiation, or just differentiation? Trends Cell Biol 2011;21:212-218.

5. Sekiguchi-Tonosaki M, Obata M, Haruki A, et al. Acetylcholine induces $\mathrm{Ca}^{2+}$ signaling in chicken retinal pigmented epithelial cells during dedifferentiation. Am J Physiol Cell Physiol 2009;296:C1195-C1206.

6. Wang $\mathrm{H}$, Loof $\mathrm{S}$, Borg $\mathrm{P}$, et al. Turning terminally differentiated skeletal muscle cells into regenerative progenitors. Nat Commun 2015;6:7916.

7. Jumabay M, Bostrom KI. Dedifferentiated fat cells: a cell source for regenerative medicine. World J. Stem Cells 2015;7:1202-1214.

8. Kramann R, Kusaba T, Humphreys BD. Who regenerates the kidney tubule? Nephrol Dial Transplant 2015;30:903-910.

9. Toda $S$, Aoki $S$, Suzuki $K$, et al. Thyrocytes, but not $C$ cells, actively undergo growth and folliculogenesis at the periphery of thyroid tissue fragments in three-dimensional collagen gel culture. Cell Tissue Res 2003;312:281-289.

10. Hoyes AD, Kershaw DR. Anatomy and development of the thyroid gland. Ear Nose Throat J 1985;64:318-333.

11. Studer H, Peter HJ, Gerber H. Toxic nodular goitre. Clin Endocrinol Metab 1985;14:351-372.

12. Teuscher J, Peter HJ, Gerber $\mathrm{H}$, et al. Pathogenesis of nodular goiter and its implications for surgical management. Surgery 1988;103:87-93.

13. Kimura S. Thyroid regeneration: how stem cells play a role? Front Endocrinol (Lausanne) 2014;5:55.

14. Hoshi N, Kusakabe T, Taylor BJ, et al. Side population cells in the mouse thyroid exhibit stem/progenitor cell-like characteristics. Endocrinology 2007; 148:4251-4258.

15. Fierabracci A, Puglisi MA, Giuliani $L$, et al. Identification of an adult stem/progenitor cell-like population in the human thyroid. J Endocrinol 2008;198:471-487.

16. Kimura S. Thyroid-specific enhancer-binding protein Role in thyroid function and organogenesis. Trends Endocrinol Metab 1996;7:247-252.

17. Ozaki T, Nagashima K, Kusakabe T, et al. Development of thyroid gland and ultimobranchial body cyst is independent of p63. Lab Invest 2011;91:138-146.

18. Li Z, White P, Tuteja G, et al. Foxa1 and Foxa2 regulate bile duct development in mice. J Clin Invest 2009;119:1537-1545.

19. Westerlund J, Andersson L, Carlsson T, et al. Expression of Islet1 in thyroid development related to budding, migration, and fusion of primordia. Dev Dyn 2008;237:3820-3829.

20. Di Palma T, Filippone MG, Pierantoni GM, et al. Pax8 has a critical role in epithelial cell survival and proliferation. Cell Death Dis 2013:4:e729.

21. Trueba SS, Auge J, Mattei G, et al. PAX8, TITF1, and FOXE1 gene expression patterns during human development: new insights into human thyroid development and thyroid dysgenesis-associated malformations. J Clin Endocrinol Metab 2005;90:455-462.

22. Mazerbourg S, Bouley DM, Sudo S, et al. Leucine-rich repeat-containing, $\mathrm{G}$ protein-coupled receptor 4 null mice exhibit intrauterine growth retardation associated with embryonic and perinatal lethality. Mol Endocrinol 2004;18:2241-2254.

23. Yamashita R, Takegawa $Y$, Sakumoto $M$, et al. Defective development of the gall bladder and cystic duct in Lgr4- hypomorphic mice. Dev Dyn 2009;238:993-1000.

24. Li XY, Lu Y, Sun HY, et al. G protein-coupled receptor 48 upregulates estrogen receptor alpha expression via CAMP/PKA signaling in the male reproductive tract. Development 2010;137:151-157. 
25. Mendive F, Laurent $P$, Van Schoore $G$, et al. Defective postnatal development of the male reproductive tract in LGR4 knockout mice. Dev Biol 2006;290:421-434.

26. Mohri Y, Kato S, Umezawa A, et al. Impaired hair placode formation with reduced expression of hair follicle-related genes in mice lacking Lgr4. Dev Dyn 2008;237:2235-2242.

27. Kalisnik M. A histometric thyroid gland activation index (preliminary report). J Microsc 1972;95:345-348.

28. Bocian-Sobkowska J, Malendowicz LK, Wozniak W. Morphometric studies on the development of human thyroid gland in early fetal life. Histol Histopathol 1992;7:415-420.

29. Bocian-Sobkowska J, Wozniak W, Malendowicz LK. Morphometric studies on the development of the human thyroid gland. II. The late fetal life. Histol Histopathol 1997;12:79-84.

30. Moskalenko R, Romanyuk A, Logvin A. Intrafollicular pressure of colloid thyroid gland determinate the type of folliculogenesis. Georgian Med News 2012; 67-73.

31. Wollman SH, Herveg JP, Tachiwaki O. Histologic changes in tissue components of the hyperplastic thyroid gland during its involution in the rat. Am J Anat 1990;189:35-44.

32. Gerard AC, Denef JF, Colin IM, et al. Evidence for processing of compact insoluble thyroglobulin globules in relation with follicular cell functional activity in the human and the mouse thyroid. Eur J Endocrinol 2004;150:73-80.

33. Terada T. Huge clusters of embryonic stem cells in human embryos: a morphologic study. Microsc Res Technol 2014;77:825-831.

34. Million K, Larcher J, Laoukili J, et al. Polyglutamylation and polyglycylation of alpha- and beta-tubulins during in vitro ciliated cell differentiation of human respiratory epithelial cells. J Cell Sci 1999;112 (Part 23):4357-4366.
35. Li Z, Zhang W, Mulholland MW. LGR4 and its role in intestinal protection and energy metabolism. Front Endocrinol (Lausanne) 2015;6:131.

36. Tichelaar JW, Lim L, Costa RH, et al. HNF-3/forkhead homologue-4 influences lung morphogenesis and respiratory epithelial cell differentiation in vivo. Dev Biol 1999;213:405-417.

37. Fagman $\mathrm{H}$, Andersson L, Nilsson $M$. The developing mouse thyroid: embryonic vessel contacts and parenchymal growth pattern during specification, budding, migration, and lobulation. Dev Dyn 2006;235: 444-455.

38. Ekholm R. Biosynthesis of thyroid hormones. Int Rev Cytol 1990;120: 243-288.

39. Choksi NY, Jahnke GD, St Hilaire C, et al. Role of thyroid hormones in human and laboratory animal reproductive health. Birth Defects Res B 2003;68:479-491.

40. Postiglione MP, Parlato R, Rodriguez-Mallon A, et al. Role of the thyroid-stimulating hormone receptor signaling in development and differentiation of the thyroid gland. Proc Natl Acad Sci USA 2002;99: 15462-15467.

41. Hilfer SR, Searls RL. Differentiation of the thyroid in the hypophysectomized chick embryo. Dev Biol 1980;79:107-118.

42. Fayet G, Hovsepian S, Dickson JG, et al. Reorganization of porcine thyroid cells into functional follicles in a chemically defined, serumand thyrotropin-free medium. J Cell Biol 1982;93:479-488.

43. Fayet G, Michel-Bechet M, Lissitzky S. Thyrotrophin-induced aggregation and reorganization into follicles of isolated porcine-thyroid cells in culture. 2. Ultrastructural studies. Eur J Biochem 1971;24:100-111.

44. Kerkof PR, Long PJ, Chaikoff IL. In vitro effects of thyrotropic hormone. I. On the pattern of organization of monolayer cultures of isolated sheep thyroid gland cells. Endocrinology 1964;74:170-179. 